\title{
Postinternet Art of the Moving Image and the Disjunctures of the Global and the Local: Kim Hee- cheon and Other Young East Asian Artists
}

\author{
Jihoon Kim \\ Chung-Ang University
}

Follow this and additional works at: https://docs.lib.purdue.edu/clcweb

C.

Part of the Film and Media Studies Commons, and the Other Arts and Humanities Commons

Dedicated to the dissemination of scholarly and professional information, Purdue University Press selects, develops, and distributes quality resources in several key subject areas for which its parent university is famous, including business, technology, health, veterinary medicine, and other selected disciplines in the humanities and sciences.

CLCWeb: Comparative Literature and Culture, the peer-reviewed, full-text, and open-access learned journal in the humanities and social sciences, publishes new scholarship following tenets of the discipline of comparative literature and the field of cultural studies designated as "comparative cultural studies." Publications in the journal are indexed in the Annual Bibliography of English Language and Literature (Chadwyck-Healey), the Arts and Humanities Citation Index (Thomson Reuters ISI), the Humanities Index (Wilson), Humanities International Complete (EBSCO), the International Bibliography of the Modern Language Association of America, and Scopus (Elsevier). The journal is affiliated with the Purdue University Press monograph series of Books in Comparative Cultural Studies. Contact: <clcweb@purdue.edu>

\section{Recommended Citation}

Kim, Jihoon. "Postinternet Art of the Moving Image and the Disjunctures of the Global and the Local: Kim Hee-cheon and Other Young East Asian Artists." CLCWeb: Comparative Literature and Culture 21.7 (2019): <https://doi.org/ 10.7771/1481-4374.3657>

This text has been double-blind peer reviewed by $2+1$ experts in the field.

The above text, published by Purdue University Press @P Purdue University, has been downloaded 0 times as of 02/10/ 20.

This document has been made available through Purdue e-Pubs, a service of the Purdue University Libraries. Please contact epubs@purdue.edu for additional information.

This is an Open Access journal. This means that it uses a funding model that does not charge readers or their institutions for access. Readers may freely read, download, copy, distribute, print, search, or link to the full texts of articles. This journal is covered under the CC BY-NC-ND license. 


\title{
PURDUE
}

UNIVERSITY PRESS <http://www.thepress.purdue.edu>

\section{CLCWeb: Comparative Literature and Culture}

ISSN 1481-4374 <http://docs.lib.purdue.edu/clcweb> Purdue University Press @Purdue University

CLCWeb: Comparative Literature and Culture, the peer-reviewed, full-text, and open-access learned journal in the humanities and social sciences, publishes new scholarship following tenets of the discipline of comparative literature and the field of cultural studies designated as "comparative cultural studies." In addition to the publication of articles, the journal publishes review articles of scholarly books and publishes research material in its Library Series. Publications in the journal are indexed in the Annual Bibliography of English Language and Literature (ChadwyckHealey), the Arts and Humanities Citation Index (Thomson Reuters ISI), the Humanities Index (Wilson), Humanities International Complete (EBSCO), the International Bibliography of the Modern Language Association of America, and Scopus (Elsevier). The journal is affiliated with the Purdue University Press monograph series of Books in Comparative Cultural Studies. Contact: <clcweb@purdue.edu>

\section{Volume 21 Issue 7 (December 2019) Article 9} Jihoon Kim,

"Postinternet Art of the Moving Image and the Disjunctures of the Global and the Local: Kim Hee-cheon and Other Young East Asian Artists" <http://docs.lib.purdue.edu/clcweb/vol21/iss7/9>

\author{
Contents of CLCWeb: Comparative Literature and Culture 21.7 (2019) \\ Special Issue Monstrosity and Globalization Ed. Ju Young Jin and Jae H. Roe \\ <http://docs.lib.purdue.edu/clcweb/vol21/iss7/>
}

Abstract: Jihoon Kim discusses in his "Postinternet Art of the Moving Image and the Disjunctures of the Global and the Local: Kim Hee-cheon and Other Young East Asian Artists" ways in which moving image works by East Asian artists Chen Chen-yu, Lu Yang, and Kim Hee-cheon engage the postinternet condition, a situation in which the internet and digital technologies are no longer perceived as new but as fundamentally restructuring our subjectivity and world. By opening a platform for intersecting the postinternet condition with a discourse on globalization, which has yet to be fully discussed in the existing Western-centric discourses on postinternet art, a key specificity of the postinternet art of the moving image by contemporary East Asian artists lies in its attempts to create spreadable images of multiple political, aesthetic, and cultural layers. The artists' rigorous aesthetic juxtapositions of virtual and physical spaces should be seen not simply as indicating the artists' cosmopolitan postinternet sensibilities but also as expressing their engagement with the contradictory and unstable disjunctures of the global and local in contemporary East Asia. 


\section{Jihoon KIM}

\section{Postinternet Art of the Moving Image and the Disjunctures of the Global and the Local: Kim Hee-cheon and Other Young East Asian Artists of Article}

Disclaimer: This paper contains images that some might find disturbing. If you wish to see the images, please scroll down to the end of the essay.

\section{Introduction}

The term "postinternet art" refers to various artistic responses since the late 2000 s to the situation "after" the internet and other digital technologies, from mobile interfaces to software applications, have already settled into our everyday life and are no longer perceived as "new" but as "banal" (McHugh 16). Although there have been divergent definitions of this term, the existing discourse on postinternet art has identified two common characteristics. First, while digital art practices are grounded in their specific platforms, such as the net or specially designed interactive interfaces, the expressions of the digital in the practices of postinternet art can be made and displayed in different versions, artifacts, and platforms. In this context, postinternet artists have tended to exhibit their artworks both on the web and inside gallery walls, thereby attempting to dissolve the boundary between the virtual and the real (Vierkant). Second, this multiplicity of digital-based or internet-driven expressions on both virtual and material platforms indicates the extent to which our sensibility, subjectivity, and life are fundamentally reconstructed under the influence of the digital and the internet. For instance, artist and curator Marisa Olson, who is known for first coining the term postinternet, argues that postinternet art is the "art that embodies the conditions of life in network culture" (quoted in Warner 195). Similarly, Michael Connor considers as a key condition of postinternet art the erosion of the "boundary between time spent online and off.... with the proliferation of smartphones and the growing pressures of an attention-based economy" (61). Given these two common features, I define postinternet art as an array of artistic production that focuses its attention on the cultural impact of the internet and digital technologies, attempts to overcome the dualities of the material and the virtual, and translates technologically influenced expressions, activities, and identities into multiple forms and experiences. As this trend in contemporary art has increasingly influenced many young practitioners because of the establishment of global media software and networks governing the production, circulation, and consumption of images and information during the last decade, a question posed by this situation is how artists in non-Western regions reconcile the global repertoires of postinternet aesthetics, techniques, and sensibilities with their expression of local culture and politics.

In response to this question, this paper discusses a few East Asian artists who have produced an array of moving image works reflective of the postinternet condition. By examining the ways in which these artists activate the hybridity of the forms, techniques, and aesthetics to express the fundamental mixture of virtual datascape (derived from user experiences of VR, video games, cellphones, etc.) with physical space or the human body, I demonstrate how their worldwide but regionally varied figurations of the postinternet condition engage and incorporate the impacts of globalization that permeate their local or regional contexts of culture, politics, environment, and urban infrastructure. These figurations, I argue, present complex disjunctures of the global and the local as artists' regional responses to the dissolution of human, cultural, and environmental boundaries. These responses, then, encompass playful fascination, critical reflection, fear, and anxiety. I particularly focus on the works of Korean artist Kim Hee-cheon, in that a particular mode of his artistic expression employed in his video pieces, the essayistic mode, not simply testifies to his creative application of postinternet techniques, aesthetics, and sensibilities but also functions to conjure up dynamic and multifaceted images of Seoul as a global metropolis imbued with the contradictions or fissures of contemporary Korean culture and politics. Before moving on to investigating the East Asian currents of the postinternet art of the moving image, it is worth establishing the affinities between discourse on the postinternet condition and theories of globalization.

\section{The Postinternet Condition, Globalization, and Super-hybridity in East Asian Artists}

Two leading figures in contemporary art, curator Nicolas Bourriaud and artist/theorist Hito Steyerl, have suggested ways in which the postinternet condition has not only been fueled by the global dissemination of images, techniques, and information but has also developed strategies for dealing with globalization, thereby reconfiguring our world and subjectivity. Bourriaud's now-famous concept of "postproduction" refers to the dominance of recycling, refashioning, and recombining existing media information and 
forms over the production of new artwork. He argues that forms of postproduction, such as sampling and remaking, are influenced by the popularity of technical tools and information behaviors provided by the internet and software applications, and these forms encourage artists "to consider global culture as a toolbox, an open narrative space rather than a univocal narrative and a product line" (Postproduction 94). Steyerl expands on Bourriaud's concept by associating it with another application of the term postproduction, which traditionally meant an array of technical procedures such as editing, mixing, 2D or 3D animation and modelling, and visual effects after shooting a film. While considering the impact of software-based postproduction beyond the worlds of art and cinema and instead as one of today's capitalist modes of production, Steyerl also envisions that the global proliferation of postproduction tools and aesthetic forms could enable artists and users to construct new bodies and images of the world that give expression to and critique that condition of life. "We can reedit the parts that were cut-whole countries, populations, even whole parts of the world, of films and videos that have been cut and censored because they do not conform to ideas of economic viability and efficiency," she writes, "We can edit them into incoherent, artificial, and alternative political bodies" ("Cut! Reproduction and Recombination" 187). ${ }^{1}$ In her ensuing polemical essay "Too Much World: Is the Internet Dead?", Steyerl underlines how the capacities of postproduction techniques to compose or reedit the bodies or worlds can serve for the strategies of postinternet art to intervene in the accelerated circulation of images in the digital environment and their incessant proliferation in our real space, experience, and subjectivity. She claims that in the age of digital capitalism the techniques of postproduction cope with the situation where the internet has become not just an interface but also an environment that has integrated older media, existing economic and cultural structures, and objects and subjects into networked matter in the form of ever-changing and fluid images. "Networked space is itself a medium, or whatever one might call a medium's promiscuous, posthumous state today," Steyerl writes, "It is a form of life (and death) that contains, sublates, and archives all previous forms of media. In this fluid media space, images and sounds morph across different bodies and carriers, acquiring more and more glitches and bruises along the way" ("Too Much World" 443). Here, it becomes obvious that the networked space that integrates all the "previous forms of media" is equivalent to the global mediascape in which images, sounds, and information "morph across" and dissolve the existing boundaries of identity, nation, and culture on a transnational scale. What Steyerl calls "glitches and bruises," then, can be seen as the markers of indeterminacies and contradictions that are generated when the digital radically influences traditional assumptions of subjectivity and world, including the distinctions or hierarchies of nature and technology, reality and illusion, the spiritual and the material, and the human and the artificial.

Despite what Bourriaud and Steyerl suggest, it is a bit surprising that scholars have not rigorously stressed a key correspondence between the postinternet condition and the consequences of the economic, technological, and cultural operations of globalization. Just as Bourriaud and Steyerl commonly point out the dissolution of the boundaries between the virtual and the real, or the dynamic layering of the two, as symptomatic of the postinternet condition, discourse on globalization has already indicated it. Here it seems to be sufficient to cite several thinkers on globalization to illustrate this correspondence. For instance, Mark Poster writes that "the assemblage of human and information machine," which suggests the postinternet condition, is "a phenomenon unprecedented in the array of media technologies, an innovation that is drastically changing the character of culture" ("Global Media and Culture" 15). Recalling Steyerl's characterization of the networked space as "fluid media space," he further suggests that the fundamental link of the human with information results in deepening the dialectical negotiation between a global flow of technological influence on culture and its multiple currents that echo an influential account of globalization: on the one hand, that link "introduces new configurations of the binaries of space and time, body and mind, subject and object, producer and consumer, indeed all the constituents that form cultures" (19); on the other hand, this media culture is also "multicentered; its voices, practitioners, and inventors deriving from all corners of the earth, violating assumptions about center and periphery, North and South, first and third worlds, Western and non-Western, imperial and subaltern, colonizer and colonized" (29). The dialectic of a universal technocultural flow and its regional variations is read as creating the complex coexistence of heterogeneous elements both in the globalized peripheries and their artistic and cultural productions. As Saskia Sassen points out regarding the economic, urban, and cultural conditions of global cities, "the ascendancy of finance and the dematerialization of many economic activities assume their full meaning only when we

${ }^{1}$ It should be further remarked that Steyerl's idea of postproduction is inseparable from her concept of the "poor image," a copy of an original image whose status becomes unstable as it is subject to the processes of uploading, downloading, compression, and deterioration in the digital economy of image production and circulation ("In Defense of Poor Images" 31-45). 
juxtapose the uneven temporalities they foster-juxtapositions that illustrate, for example, the disjuncture of digital and material temporalities" ("Spatialities and Temporalities of the Global" 222). Sassen's view of the disjuncture of digital and material temporalities and spatialities as a characteristic of global cities and their digital infrastructures of "dematerializing economic activities" echoes Arjun Appadurai's famous concept "technoscape" which he defines as follows: "By technoscape, I mean the global configuration, also ever fluid, of technology and the fact that technology, both high and low, both mechanical and informational, now moves at high speeds across various kinds of previously impervious boundaries" (Modernity at Large 34).

What one can read from the leading discourse on globalization as summarized above are its two key consequences, the high-speed circulation of cultural products and economic values and the dissolution of previously existing cultural, economic, and geopolitical boundaries. These are also identified in discourse on postinternet art, which has placed greater emphasis on the fundamental imbrication of the virtual and the real, due to the popularization of internet-based behaviors, images, tools, and data. If we consider the internet, as Stephanie Bailey has neatly summarized, to be "a vast network that connects localities within a global framework... [that is], a 'space' mapped out over material space"("Ourspace" 129), it can also be seen as interacting with various cultural, economic, and political realities of the local, including non-Western regions. Indian artist group Raqs Media Collective has discussed the demand for intersecting the postinternet condition with the global/local dynamics as follows: "The momentum generated by different processes of cultural articulation set in motion in various local contexts all over the world indicate a reality of densely networked yet autonomous tendencies, movements, genres, styles, and affinities that are far more complex than those for which the discourse of Westernization allows"( Digressions from the Memory of a Minor Encounter" 83-4). The idea of superhybridity, the term coined by curator Jörg Heiser, can be read as suggesting the East Asian moving image artists' technical and aesthetic strategies to express these intersections of the postinternet art and the global/local disjuncture. He defines super-hybridity as an aesthetic response to the digital's fundamental rebooting or reformatting of the world and subjectivity after cultural hybridization as a consequence of globalization: that is, super-hybridity "[is] a reflection of how hybridization has moved beyond the point where it's about a fixed set of cultural genealogies and instead has turned into a kind of computational aggregate of multiple influences and sources" ("Pick and Mix").

Vapor Equilibrium (2017) by Taiwanese artist Chen Chen-yu complicates the circuit of the global and the local in the East Asian postinternet art of the moving image by adding his speculation on the PanAsian flows of culture, data, and fine dust. The work develops multidimensional reflections on the situation that images are copied, pasted, and uploaded on a massive scale, and that these images infiltrate our social space at political, industrial, environmental, and cultural levels. In so doing, it employs and visualizes the metaphor of a cloud to demonstrate how it cuts across different phenomenadata storage in cloud computing, air pollution in China and Korea, pan-Asian circulation of K-pop, mobility of Chinese tourists, and the shortage of minerals in the Chinese electronics industry-and renders them to echo each other. Chen's reliance of the cloud metaphor for configuring and intersecting the multiple speculations of the cultural, environmental, and industrial issues reminds us of what Tunghui Hu and John Durham Peters discuss regarding the concept of the cloud. For Hu, the word "cloud" "speaks to the way we imagine data in the virtual economy traveling instantaneously through the air or 'skyway'-here in California one moment, there in Japan the next" ( $A$ Prehistory of Clouds xi). Peters supplements Hu's view on the cloud as the incarnation of data flow by establishing its meteorological dimension as a medium that blurs the boundaries between the virtual and the real, and between the human and the natural: "Today natural facts are media, and cultural facts have elemental imprint. We can see the Internet as a means of existence, in some ways close to water, air, earth, fire, and ether in its basic shaping of environments" (The Marvelous Clouds 49).

In order to portray these multiple metaphorical dimensions of the cloud, which suggest that the global circulation of digital data restructures our environmental, meteorological, and cultural conditions, Chen relies on such postproduction tools as remix and superimposition. The various videos that he shot to document urban details of China, Korea, and Taiwan are distributed in small frames across a larger background image of clouds that he captured from a YouTube video (figure 1). Activating the aesthetic of super-hybridity, this superimposition is combined with his authorial commentary on how the movement of clouds is identical to the flow of images and cultures as the clouds connote both environmental changes and data storage in remote computing. These multiple connotations of the clouds are also further highlighted as he incorporates in his screen more YouTube videos that document air pollution in Seoul and Beijing due to fine dust. Besides superimposing and remixing YouTube videos, Chen's expression of super-hybridity culminates in the fictional "Internet Weather Report" sequence, in which a female weather forecaster reports the flows of clouds and fine dust in association with the rapid 
production of selfies and videos about Korean cuisine and tourist spots thanks to the pan-regional popularity of Korean dramas (such as Guardian, The Heirs, My Love from the Star), the decrease in the number of Chinese tourists travelling to Korea due to the Chinese government's measures against Korea's installment of THAAD (Terminal High Altitude Area Defense) in 2017, and the rarity of minerals in Bantou, China, due to the large-scale mining for the demand of the Chinese digital industry (figure 2). Marked by the density of information and YouTube videos and selfies overlaid on the 3D Google Maps images of the East Asian region, this sequence pays homage to the weather forecast sequence in Steyerl's Liquidity Inc (2014), a video work that presents her speculation on the identity of images and things in the postinternet condition, as well as her use of the metaphor of liquidity to suggest the global economic, political, and environmental crises. As the "Internet Weather Report" sequence demonstrates, however, Steyerl's influence on Chen negotiates with his engagement with the local and transnational mobility of cultural products, tourists, and fine dust in the East Asian region (see figures 1 and 2 at the end of the essay).

The moving image works of Chinese artist Lu Yang have testified to the complex intersections of the local and the global as her rigorous employment of open-source and professional 3D graphic animation tools juxtaposes Chinese ideas of corporeality and spirituality with contemporary technological, biological, and medical imaginations. In several interview. Lu has specified body and religion as two most recurring subject matters encompassing her body of work: 'When I was a child, I spent a lot of time in hospital emergency rooms because I had asthma. So naturally I became interested in the idea of medical treatment and the body...[And] I often read my grandmother's books about Buddhism, which made me really interested in religion' (quoted in Qin, "Q\&A"). Along with her obsession with Chinese religious symbols and ideas, Lu's interest in the Western medicine, anatomy, and neuroscience has repetitively been reflected in her works of the moving image, such as The Cruel Electromagnetic Wave about Absolute Zero (2013), Uterus Man (2013), and Moving Gods (2015). Delusional Mandala (2015), a highly mesmerizing 3D animation, expands Lu's exploration of posthuman subjectivity in relation to science and technology into a more full-fledged postinternet imagination characterized by the aesthetic of super-hybridity. For this work, Lu is transformed into a virtual avatar via 3D scanning technology. This avatar is continuously manipulated by the extensive software environment in which anatomy, neuroscience, and religion are deeply hybridized. Two neurological experiments are made on Lu's avatar that undergoes simulations of a neurological disorder and stages of dying. As in her previous works, Lu superimposes medical and religious perspectives on human consciousness and body, thereby challenging the dichotomy of the two. The 3D virtual images of medical experiments, including simulations of Lu's bodily organs and brain, are juxtaposed with Chinese religious icons. The dissolution of the boundaries between science and religion culminates in the animation's last sequence, in which a hearse is constructed from a 3D model and decorated with an ornate Chinese roof, a lotus pedestal, traditional Chinese patterns of flowers and ribbons, and LED screens that display portraits of Lu's avatar wearing the prosthetic tool of the stereotactic system.

Lu's fast-paced editing punctuates the operation of the 3D scanner through which her real face is transformed into digital 3D wire-framed models, while also highlighting the equivalence and interchangeability between the models and her digital avatar: that is, all the organic and mechanical details, such as brains, internal organs, prosthetic tools for stereotactic mapping, and the brain or magnetic simulations, emerge as images created and processed by the same software environment filled with grids and data (figure 3). Lu's virtual avatar and her bodily components are as flexible as the data and tools used for the mapping and simulations, and both types of images internalize the codes and algorithms of the software whose operation enables them to appear. Lu's self-reflexive experiment with 3D scanning here stresses that all these images are no longer limited to the virtual environment but fundamentally redesign our corporeal subjectivity in ways that dissolve the boundaries between the virtual and the real, and between online and offline. In so doing, Lu also suggests that all these images deeply infiltrate not simply physical spaces and organic bodies, but also affective and spiritual domains such as emotion, religion, and afterlife. Lu's avatar firstly undergoes stereotactic surgery, which in turn propels the avatar to experience a series of emotional responses (such as joy, sorrow, anger, etc.) triggered by activities in the somatic nervous system. These responses also lead to a religious fantasy in which the avatar's prosthetic tool for stereotactic surgery is transformed into a golden nimbus (which symbolizes holiness) and she is multiplied against the backdrops of Buddhist mandala icons (figure 4). Metabolism, religion, and death are thus programmable in Delusional Mandala: their corresponding images are expressive of the same digital system that is fundamentally naturalized in our world, body, and mind. This awareness that everything is connected and subject to the same digital system echoes James Bridle's reflection on the ontology of the image in postinternet art: "Each image is a link, hardcoded or imaginative, to other aspects of a far greater system, just as every web page and every 
essay...is a link to other words, thoughts, and ideas" ("The New Aesthetic and Its Politics" 23). In this sense, Delusional Mandala vividly illustrates how digital software's 3D virtual space is now capable of simulating and incorporating previous media techniques and expressions, and of reconstructing our body, mind, and reality in posthuman and postinternet fashions. More than relying on 3D virtual space's compositing paradigm of interacting with and remixing already existing media expressions, Lu creates her digital images as a hybrid of the virtual and the real. Her avatar and virtual realm point to Steyerl's insight on the world after the internet stopped being a new utopia or possibility, a world in which our body and mind are deeply linked to the images that are subject to infinite circulations and diverse manipulations governed by the operations of networks and software applications. Steyerl writes, "Reality itself is postproduced and scripted, affect rendered as aftereffect...far from being opposites across an unbridgeable chasm, image, and world are in many cases just versions of each other" ("Too Much World" 444).

\section{Kim Hee-cheon's Videos: Postinternet Essayistic Subjectivity and Seoul}

Kim Hee-cheon's single-channel video trilogy, Lifting Barbells (2015), Soulseek/Pegging/Air-Twerking (2015), and Wall Rally Drill (2015), connects the subjectivity and form of the personal essay film to represent the fundamental equivalence of the virtual and physical worlds under the postinternet condition. The essay film, a nebulous method of filmmaking that crosses the boundary between fiction and nonfiction cinema, between documentary and experimental film, between the public and the personal, and between the intellectual and the poetic, lays the groundwork not simply for the three videos' textual hybridity and heterogeneity, but also for Kim's own drifting, pessimistic consciousness that reflects on the dissolution of the virtual and the real. A key affinity of the essay film with the postinternet condition lies in its reflectivity and subjectivity, two features that the existing scholarship of the essay film has identified as specific and essential. For Laura Rascaroli, the essayistic form of cinema presents "the expression of a personal, critical reflection on a problem or set of problems" ("The Essay Film" 35). While this reflection originates from the filmmaker's authorial voice, its multiple, sometimes contradictory, positions and modes of thinking, which often result in the film's textual digression, transgression, multiplicity, and fragmentation, do not affirm a cause-and-effect account of the problem or an objectivist truth to be discovered, but suggest his or her particular subjectivity that Michael Renov identifies as 'a site of instability - flux, drift, perpetual revision rather than coherence'"(The Subject of Documentary 110). Besides reflectivity and subjectivity, I would highlight the parallel between the global and the local as another affinity of the essay film and postinternet art. In his recent take on the essay film, Thomas Elsaesser ascribes its global popularity to its capacity "to adapt and to morph, to be flexible and open, [and] to be both a sponge and a probe" "The Essay Film" 247). Elsaesser's observation of the amorphousness of the essay film corresponds to Steyerl's insight into its global dissemination: "The essay as form has adapted rather well to globalization," she writes, "It offers specificity, but beyond local academics or artistic codes. It is more often than not transnational...It is unaffiliated, radically independent, but also mobile, and can be integrated into newer and newer chains of meaning and different contexts" ("The Essay as Conformism?" 277). By taking advantage of the essay film's technical and aesthetic assets that contribute to its global popularity in the digital realm, including its penchant for the fluid mixture and transformation of multiple voices, images, and windows, Kim establishes his three videos as the space of super-hybridity. What is foregrounded in this space, then, is Kim's fluid authorial subjectivity that, based on his stay in Argentina for a year before his return to Seoul, searches for and questions his existential position, vacillating and split between the networked world subject to constant transformation and warping and today's globalized world in which the geographical distance between one place and another is fundamentally collapsed.

Lifting Barbells develops the artist's self-reflexive, semi-autobiographical narrative about his persona who tracks down the final moments of his father who died in a car crash. The persona's quest develops as he investigates his father's smartwatch that left his GPS data and cardiogram on its website and the trajectory of his car via the virtual map of its navigation system, imagining his father "entering the woods of data, the forests of gravestones. The infographic images of his cardiogram that visualize his father's exercise and the speed of his heartbeat on the day of his death, together with the images of the virtual map, express the extent to which the persona's consciousness of himself, his others, and his world is fundamentally built upon the picture and language of datascape. However, the video's narrative also digresses from the persona's quest for the memory of his father, as is presented in his voice-over that narrates an email correspondence with Lyudmila, his former girlfriend, whom he met in Argentina. This voice-over tells the persona's confused state of mind that recognizes his surrounding world as a 
deserted ruin, imagines the end of the world, and even perceives its ominous signs in the seemingly ordinary urban environments of Seoul.

This foreboding sense of impending apocalypse and the fictional subject's decentralized drifting across the virtual and the real worlds are varied in Soulseek/Pegging/Air-Twerking, in which the subject comes to recognize everything-his physical world, his surrounding people, and objects-as data. As in the case of Lifting Barbells, the persona of this video shuffles between the urban space of Seoul, his cramped room, and the datascape that consists of a large number of photos, graphic images, and music files that he accumulated and stored in his computer. Its narrative, too, digressively leaps across different stories expressing the subject's decentralized and fluid consciousness, from his imagination of exporting himself to the virtual world, to his illusion of the indiscernibility of the virtual and real worlds, and to his self-confession about how long he collected the images and audio files and how much storage they occupy.

The subject's continual, overlapping journey between the virtual and the real is once again repeated in Wall Rally Drill, its title explicitly signifying the act of going back and forth. It starts with the persona's reflection on the death of the world, triggered by his witness of the death of a pigeon, which functions as a gloomy portrait of a human being that is trapped in a world without a solid boundary between the real and the virtual. This reflection is extended into the world of an online chatting service, in which the persona meets with a mysterious man who teaches him the following lesson: "your head is full of the data of the illusory world. You have to kill yourself in the world, like thinking of erasing the data in your hard disk." Roaming around different streets in Seoul, he even imagines importing what he experienced in the early summer to the early winter of his day while also developing an illusion that his surrounding people are imported from here and elsewhere, and that they disappear being ignorant of where they are now. Throughout this trilogy, Kim's subjectivity hovers between his satirical celebration of the worldas-data and his pessimistic view of the world as deserted and decayed. Again, this ambivalent position attests to Kim's refashioning of the essay film, its textual open-endedness and fluidity, and its selfquestioning yet decentralized subjectivity and flow of thoughts.

A key feature of the essay film lies in the freedom to employ various audiovisual components (liveaction images, found images drawn from various sources, texts, voice-over commentaries, etc.) and multiple modes of enunciation. Thus, the essay film and video correspond with the pervasive use of digital postproduction tools to create the hybridity of different visual layers, including the mixture of the real and the virtual. This aesthetic feature can be found in a number of contemporary moving image works that portray postinternet subjectivity, the world, and sensibility. Kim's videos are in line with this global trend in their technical and aesthetic dimensions. He pervasively uses the techniques of postproduction, such as the appropriation of clips from YouTube and information from news portals, and 3D rendering. His reliance on these techniques are intimately connected to Steyerl's idea on the art of "postproducing, launching, and accelerating [an image]" ("Too Much World" 37) in postinternet conditions.

What is notable in Kim's video essays is that their fictional self and diegetic space do more than express the reformulation of the world and subjectivity as images, a universal trope of postinternet art on its global scale: more significantly, the three videos' distinction should be found in Kim's association of this trope with investigating and reflecting on the infrastructural, cultural, and psychic dimensions of Seoul as a local version of the global city. Kim's awareness of the world and of himself is structured by his occupation of social media timelines, in which the distinction between the virtual and real worlds, as well as temporal and geographic differences, are blurred, as the fictional self in Wally Rally Drill compares his life to the "empty rally between the two worlds." In Kim's video trilogy, his persona's hovering between Argentina and Seoul and his imagination of importing the early summer to the early winter suggest how the overlapping of multiple times and selves in the virtual world meets with Kim's cosmopolitan sensibility of feeling the collapse of the boundaries between here and elsewhere and the jetlag caused by the simultaneous pressure of different timelines. However, the persona's cosmopolitan sensibility mixed with his loss of self-control faced with the fundamental blending of the virtual and the real entails his keen observation of the urban landscapes in Seoul and his creative visualization of the landscapes as datascape. In Lifting Barbells, the persona's comment that "the bicycle path that his father took has been flattened into a pile of data" is overlapped with the images of a deserted island on Hangang river. The sense of emptiness and decadence, suggested by these vacant images, is extended into several aerial Google Map views of Lotte World, a representative theme park filled with thrilling rides, parades, and shopping malls in Seoul. The black-and-white images of this landmark spot in Seoul undermine its ideal visualized in the vertical and all-encompassing view, namely, the park as the center of the postmodern global metropolis representing Asia, in combination with the persona's cynical comment characterizing it as "encountering the entire field of Asian dreams." This deconstruction of the 
ideal of the theme park is amplified as its black-and-white images are reimagined as a deserted ruin in which "our gravestones are loading right now" (figure 5). The sense of impending apocalypse presented in this sequence culminates in the last moments of Lifting Barbells, in which a swarm of zombie-like 3D human avatars populate subway trains and around a bridge on the Han river (figure 6). Here, the hybrid juxtaposition of photographic 2D and virtual 3D contributes to connecting a key trope of postinternet art, that is, rendering the virtual image or data-image as the world and subject itself, to expressing the urban infrastructures of Seoul, such as the subway and bridge, as permeated with digital information, expression, space, and time.

Kim's trilogy videos echo Steyerl's two arguments on the postinternet condition. The first is that in the situation that digital technologies determine its production, circulation, and consumption, the image itself does not represent the reality outside of it: rather, the image "is a fragment of the real world. It is a thing just like any other-a thing like you and me" ("A Thing Like You and Me" 52). The second is that this post-representational condition, in which the image is identical to things, the world, and the human being, affects not simply the way that we understand the world, but also our vision, identification, and self-awareness. In "In Free Fall: A Thought Experiment in Vertical Perspective," Steyerl argues that the rise of vertical, aerial views in our digitally driven contemporary visual culture deconstructs the traditional linear perspective that "creates the illusion of a quasi-natural view to the 'outside', as if the image plane was a window opening onto the 'real' world" (18). Curiously enough, Kim's awareness of this post-representational situation is applied to the virtual window of the computer or online world, as well as to the window that materially structures our world and our vision of it. This is the reason that in Soulseek/Pegging/Air-Twerking and Wally Rally Drill the fictional self declares that not simply the world itself but also ourselves become the window. For instance, the mysterious guy that the artist's persona meets online in Wally Rally Drill declares that "our living world is just the glass façade, and we are no more than the liquid crystal of the cellphone we have." Again, this postinternet sensibility of the identity of the image and world, of self and window, is built around Kim's keen observation of the Lotte World Tower, a super-tall skyscraper opened to the public in 2017, the tallest building in South Korea and the fifth tallest building in the world, as the most prevailing image of the last two works of the trilogy (figure 7). More than highlighting the building's status as the symbol of the compressed industrial modernity that has elevated Seoul to one of the largest cosmopolitan metropolises, the building's surfaces of glass windows, along with the refraction of light on the surfaces, bear witness to the dissolution of the boundaries between the virtual and the real in the material and infrastructural aspects of Seoul, while also being connected to the juxtaposition of the two-dimensional and the three-dimensional in Kim's datascapes of the trilogy. Then, the windows and their reflection of light allude to the fractured urban reality in Seoul, and the debris of this corrupted, degraded reality pervades across the immaterial and material worlds in Kim's trilogy in the forms of the poor images. One notable image form found in Soulseek/Pegging/Air-Twerking is a warped 3D graphic image. First it is used to visualize the data stored in the computer of the fictional subject and self-reflexively expose Kim's reliance on 3D modeling and rendering. Later, this image form is extended into an array of surreal and grotesque images that portray Kim's delusion about Seoul's urban, cultural, and political realities, as the images present cars, signs for snack bars, churches, icons of Christianity, his self-portrait populated by junk in his studio, and even Korea's national flag (figure 8). Here, Seoul's material, political, and psychic dimensions are rendered to be the debris of digital data, and Seoul itself is imagined as a kind of digital junkspace. Again, these distorted and messy digital images do more than configure Kim's fluid and confused subjectivity; Seoul portrayed as digital junkspace reflects his awareness of it as a fissured or distorted metropolis in which the global and local meet in contradiction.

Kim's Sleigh Ride Chill (2016) represents the postinternet condition under which digital technologies and their image-based forms of experience are deeply enmeshed within the metropolitan landscape of contemporary Seoul as well as the lives of its inhabitants, by intersecting three different narrative threads: the first is about a male amateur club DJ who lost his laptop and had all of his private information leaked on the internet; the second foregrounds a young male named Porky-Daddy, who streams his playing of a classic racing game Grand Turismo 4 (a fictional parody of Grand Theft Auto) via a personal online broadcasting platform. From the video's beginning, his direct address to a webcam says he will play and air a Korean TV show because it will take about 30 hours for him to finish the race. The show comprises the final thread, which takes the form of a fictional national broadcasting report that covers the stories of a new "suicide club" in Seoul. All of these intertwined stories, if presented in extremely fragmented and fast-paced ways, provide viewers with a kinesthetically playful critique on a key aspect of contemporary Korean society: that is, the society's technological infrastructure has already developed so highly that its residents have begun to recognize their own subjectivity, behavior, and environment as digitally produced and influenced. The video's juxtaposition of the three stories is read 
as a variation of the essayistic mode in his trilogy, not simply because the video develops multiple spaces and temporalities, but also because the fictional selves of the first and second stories function as different incarnations of Kim's fluid subjectivity. Ultimately, the three stories are brought together to configure Seoul as what Beth Coleman calls "X-reality," a continuum of dynamic and multifaceted exchanges between virtual and real spaces. The interconnection of the multiple X-realities presented by the three narrative threads suits Coleman's assumption that the pervasive use of different digital media platforms and interfaces-in the case of Sleigh Ride Chill, laptops, search engines, video games, and 3D applications - "defines a world that is no longer either virtual or real but representative of a diversity of network combinations" (Hello Avatar 4).

Kim employs the techniques of postproduction to exert this juxtaposition of play with and critique on the postinternet condition of contemporary Korean society. As a result, the images in Sleigh Ride Chill are seen as a surface on which the boundaries between the real and the virtual are fundamentally blurred; or they are aesthetically indicative of the extent to which the virtual deeply restructures the physical reality of the metropolis and the mental reality of its inhabitants as overlapped and fluid. In the story of the DJ, he explains that after having his laptop and cellphone lost, "It felt like I was sort of expanding somehow [and] my outlines have dissolved. The 'outside' doesn't exist anymore. Everyone in this world breathes in and out of my data." To indicate this point, Kim employs not simply multiple windows for framing the subject's understanding of the world within portal sites or social media platforms, but also VR visualizations and face swap interfaces and applications. In particular, face swap, an effect of switching faces that is now easily available with desktop and mobile applications, has effectively been used to visualize how the identities of the subjects are recognized as the repetition of the same in the networked environment and how this self-awareness is overlaid with the subject's understanding of the other in the physical world. Because Kim used such applications as Snow, Faceswap Live, and Open Source Faceswap to create the effect, his own face was replicated on the faces of the others that the man who lost his cellphone and laptop encounters on the subway or Gwanghwamun streets (figure 9). Kim has confessed that this effect has to do with the changing idea of the virtual in response to the postinternet condition of contemporary Korean society as follows: "The term virtual world (kasangsegye) now seems ambiguous. The term has become so incorrect as to explain the distance or difference between online and offline, the meaning we have in our mind when we use it. Rather, might the virtual be more a state of affairs than a world? A kind of state as we mark ourselves with such commands as 'online,' 'offline, or 'left,' in NateOn" (quoted in Kwon). ${ }^{2}$

By emphasizing the aesthetic of extreme hybridity with overlapping of the three stories and dynamically juxtaposing the virtual with the real, Sleigh Ride Chill also demonstrates how the experience of social media and digital entertainment, as well as the expressive tools of software applications and digital interfaces, establishes itself as a global postinternet condition of Seoul and at the same time dynamically intersects with its local infrastructure and politics. As illustrated by the video game space of Grand Turismo 4, Kim envisages the urban space of Seoul as an intense entanglement of physical, digital and social media cultures, investigating new infrastructures and practices of circulation, materials, networked environments, and vehicles of transport. The virtual space of Seoul in the video game is portrayed as being modelled after Google Maps. The various superimpositions of news reports on the suicide club and the political events of recent Korean society over the virtual Seoul via digital compositing configure this metropolis as both the global technoscape marked by the accelerated flow of information, which is also signaled by the racing game itself, and the local mediascape permeated with local issues and politics of identity, including the gradual increase in Korea's suicide rate, and the right-wing Christian groups' demonstration against the queer parade that aimed to celebrate and support equal human rights for LGBT people (figure 10).

\section{Conclusion}

Renowned art historian Terry Smith offers three currents of contemporary art in terms of how they can be seen as different ways of artistic world-making in response to the various political and aesthetic situations of the contemporary world. The first current includes a number of artists who experimented with an aesthetic of globalization, and the second refers to various artistic practices that emerged from and reflected on postcolonial situations or histories of non-Western worlds. The third and final current led by younger artists, according to Smith, "certainly draw[s] on elements of the first two tendencies, but with less and less regard for their fading power structures and styles of struggle and with more concern for the interactive potentialities of various material media, virtual communicative networks and

${ }^{2}$ NateOn, developed by SK Communications, is a Korean instant messaging program that was once popular locally in the 2000s. 
open-ended modes of tangible connectivity" ("Currents of World-making in Contemporary Art" 183). Although Smith does not explicitly refer to postinternet art, the East Asian artists of moving image practices that I discuss in this article, I argue, attest to the vitality and viability of his third and final current in two ways. First, as I have elaborated in this essay, the affinities between postinternet art and discourse on globalization go hand in hand with Smith's observation of the final current as "drawing on" both globalization and local conditions of culture and history yet being more preoccupied with the "potentialities" and consequences of various media and digital networks. Second, Smith's idea of artistic practice as "world-making" dovetails with the strategies of world-making to respond to and go beyond the homogenizing impacts of cultural and technological globalization. In this context, world-making "references multiplicity and multiple worlds, not along the old lines of cultural exclusivity and spatial separation, but along the new logics of production" (Annesh, Hall, and Petro, "Introduction" 5).

The young East Asian artists' different ways of world-making by means of digital postproduction tools and the aesthetic of super-hybridity result in rendering the complex intersections of the global and the local as disjunctive and even grotesque images of bodies and spaces. In giving expression to the impacts of globalization on their regional culture, environment, and politics, the images can be seen as what Barbara Creed might consider "monstrous" figures (The Monstrous-Feminine 1-15), an array of grotesque representations in which the unruly and differential forces of globalization erase and redraw the previously established boundaries between various binaries, including human and non-human, technological and natural, and virtual and real. The artists' monstrous figures, again, attest to the fundamental imbrication of globalization and the postinternet condition, in that they derive from the now insurmountable proliferation of digital images, information, and interfaces in our world and subjectivity, and in that they offer us a creative and refreshed awareness of the disjunctive negotiations between globalization and the local identities, cultures, and urban infrastructures in contemporary East Asia.

\section{Works Cited}

Annesh, A. Lane Hall, and Patrice Petro. "Introduction: The Making of Worlds." Beyond Globalization: Making New Worlds in Media, Art, and Social Practices, edited by A. Annesh, Lane Hall, and Patrice Petro, Rutgers UP, 2012, pp. $1-14$.

Appadurai, Arjun. Modernity at Large: Cultural Dimensions of Globalization, U Minnesota P, 1996.

Bailey, Stephanie. "Ourspace: Take the Net in Your Hands." You Art Here: Art after the Internet, edited by Omar Kholeif, Manchester, UK: Cornerhouse, 2014 pp. 128-135.

Coleman, Beth. Hello Avatar: Rise of the Networked Generation, MIT P, 2011.

Creed, Barbara. The Monstrous-Feminine: Film, Feminism, Psychoanalysis, Routledge, 1993.

Bourriaud, Nicolas. Postproduction. Culture as Screenplay: How Art Reprograms the World. translated by Jeanine Herman, Sternberg Press, 2005, Berlin.

Bridle, James. "The New Aesthetics and Its Politics." You Art Here: Art after the Internet, edited by Omar Kholeif, Cornerhouse, 2014, pp. 20-27.

Connor, Michael. "Post-Internet: What It Is and What It Was." You Art Here: Art after the Internet, edited by Omar Kholeif, Cornerhouse, 2014, pp. 56-64.

Elsaesser, Thomas. "The Essay Film: From Film Festival Favorite to Flexible Commodity Form?" Essays on the Essay Film, edited by Nora M. Alter and Timothy Corrigan, Columbia UP, 2017, pp. 240-259.

Heiser, Jörg. "Pick and Mix: What is Super-hybridity?" Frieze, 10. September 2010, https://frieze.com/article/pickmix, accessed 1 December 2018.

Hu, Tung-Hui. A Prehistory of the Cloud. MIT P, 2015.

Kwon, Minji. "Kim Hee-cheon's Timeline." Harper's Bazaar Korea, 3 April 2017, http://harpersbazaar.co.kr/art/\%EA\%B9\%80\%ED\%9D\%AC\%EC\%B2\%9C\%EC\%9D\%98\%ED\%83\%80\%EC\%9E\%84\%EB\%9D\%BC\%EC\%9D\%B8/, accessed December 1, 2018.

McHugh, Gene. Post Internet: Notes on the Internet and Art 12.29.09>09.05.10. Brescia: Link Editions, 2011.

Peters, John Durham. The Marvelous Clouds: Toward a Philosophy of Elemental Media. U Chicago P, 2015.

Poster, Mark. "Global Media and Culture." Beyond Globalization: Making New Worlds in Media, Art, and Social Practices, edited by A. Annesh, Lane Hall, and Patrice Petro, Rutgers UP, 2012, pp. 15-29.

Qin, Amy. "Q\&A: Lu Yang on Art, 'Uterus Man,' and Living Life on the Web." New York Times. November 27, 2015, Accessed 2 September 2016. http://www.nytimes.com/2015/11/27/world/asia/china-art-lu-yang-venicebiennale.html?_r=0

Raqs Media Collective. "Digressions from the Memory of a Minor Encounter." Mass Effect: Art and the Internet in the Twenty-First Century, edited by Lauren Cornell and Ed Halter, MIT P, 2015, pp. 79-88.

Rascaroli, Laura. "The Essay Film: Problems, Definitions, Textual Commitments." Framework, 49.2 (2008): $24-47$.

Renov, Michael. The Subject of Documentary. U Minnesota P, 2004.

Sassen, Saskia. "Spatialities and Temporalities of the Global: Elements for a Theorization." Public Culture, 12.1 (2000): 215-232.

Smith, Terry. "Currents of World-making in Contemporary Art." World Art, vol. 1, no. 2, 2011, pp. 171-186. 
Steyerl, Hito. "The Essay as Conformism? Some Notes on Global Image Economics." Essays on the Essay Film, edited by Nora M. Alter and Timothy Corrigan, Columbia UP, 2017, pp. 276-286.

Steyerl, Hito. "Too Much World: Is the Internet Dead?" Mass Effect: Art and the Internet in the Twenty-First Century, edited by Lauren Cornell and Ed Halter, MIT P, 2015, pp. 439-450.

Steyerl, Hito. "In Free Fall: A Thought Experiment on Vertical Perspective." The Wretched of the Screen, Sternberg Press, 2012, Berlin, pp. 12-30.

Steyerl, Hito. "In Defense of Poor Images." The Wretched of the Screen, Sternberg, 2012, pp. 31-45.

Steyerl, Hito. "A Thing Like You and Me." The Wretched of the Screen, Sternberg, 2012, pp. 46-59.

Steyerl, Hito. "Cut! Reproduction and Recombination." The Wretched of the Screen, Sternberg, 2012, Berlin, pp. 176-196.

Vierkant, Artie. "The Image Object Post-Internet." 2010, Accessed 13 September 2016. http://jstchillin.org/artie/pdf/The_Image_Object_Post-Internet_a4.pdf

Warner, Nick. "The Symptoms of Connectedness: In Conversation with Marisa Olson." Art after the Internet, edited by Phoebe Stubbs, Black Dog, 2013, pp. 184-199. 

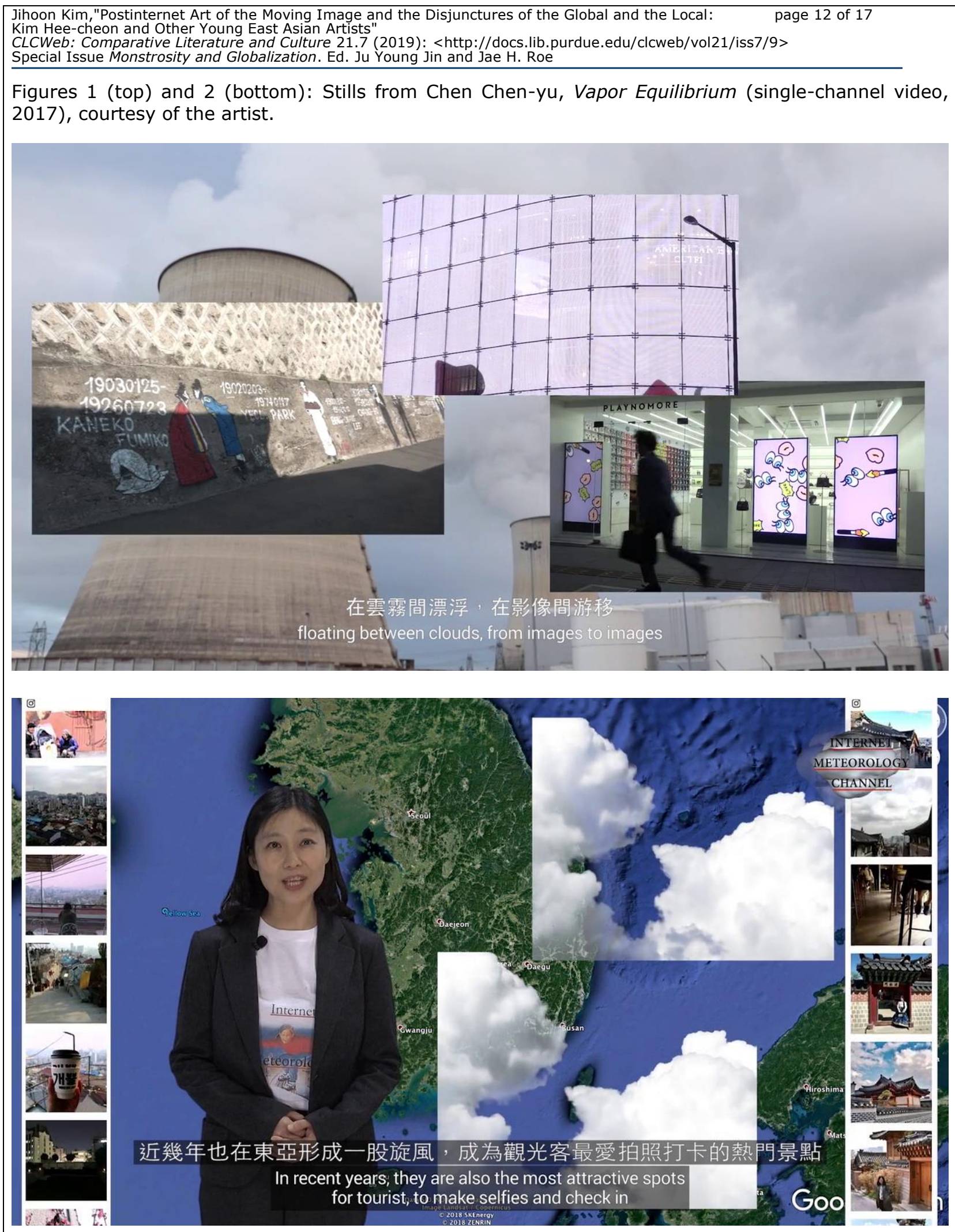
Jihoon Kim,"Postinternet Art of the Moving Image and the Disjunctures of the Global and the Local:
Kim Hee-cheon and Other Young East Asian Artists"

page 13 of 17

CLCWeb: Comparative Literature and Culture 21.7 (2019): <http://docs.lib.purdue.edu/clcweb/vol21/iss7/9>

Special Issue Monstrosity and Globalization. Ed. Ju Young Jin and Jae H. Roe

Figures 3 (top) and 4 (bottom): Stills from Lu Yang, Dimensional Mandala (single-channel video, 2015), courtesy of the artist.
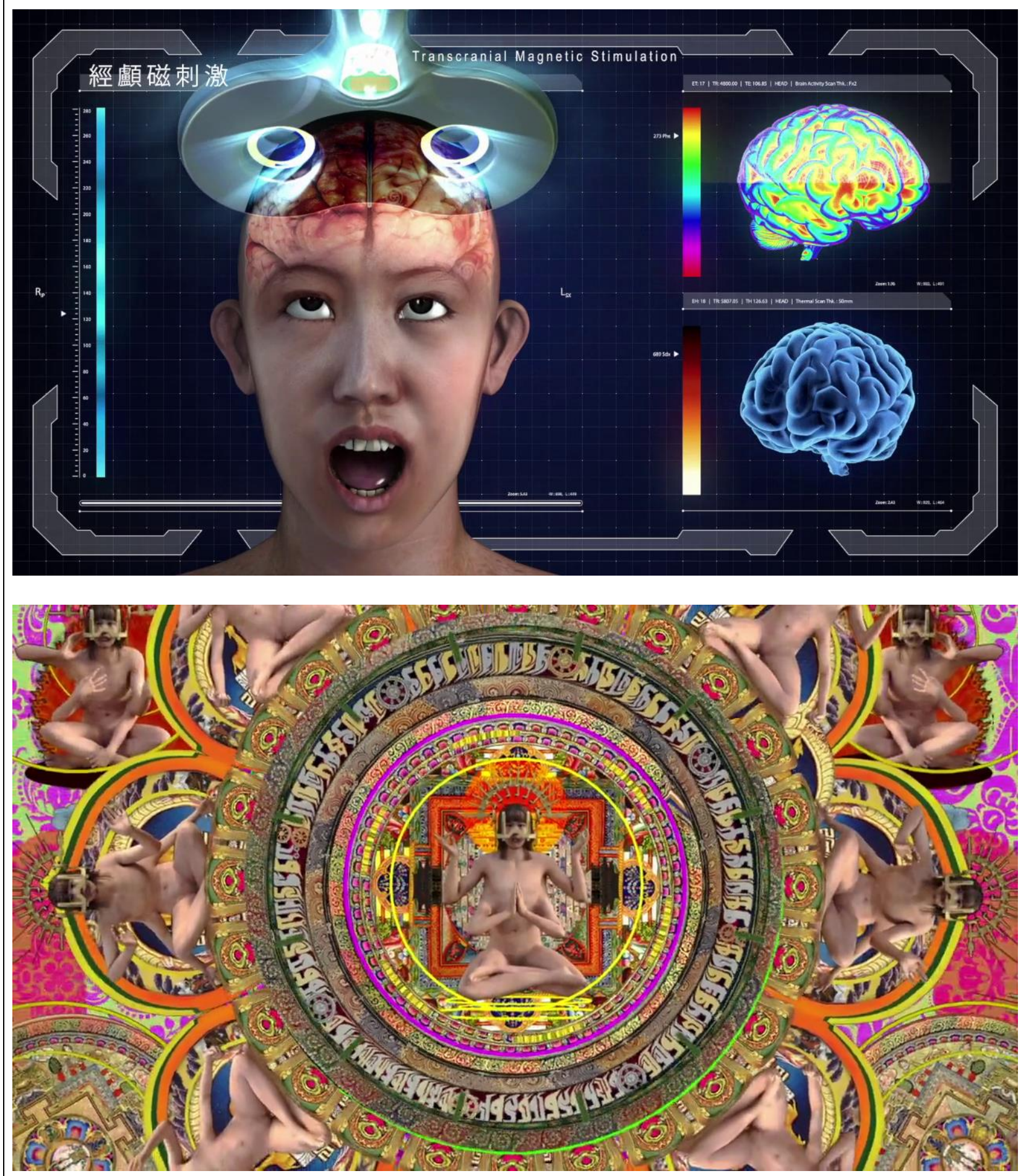

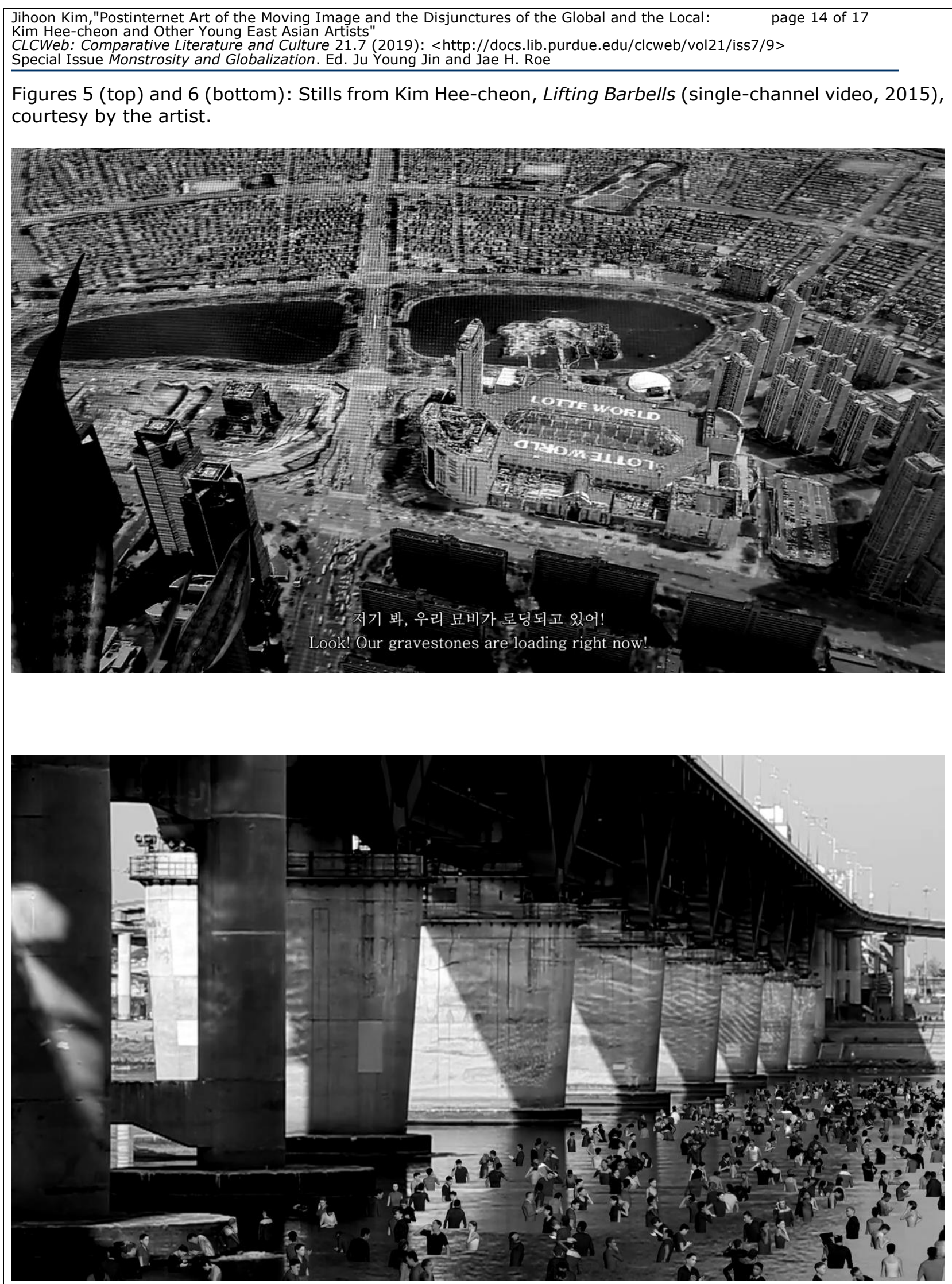

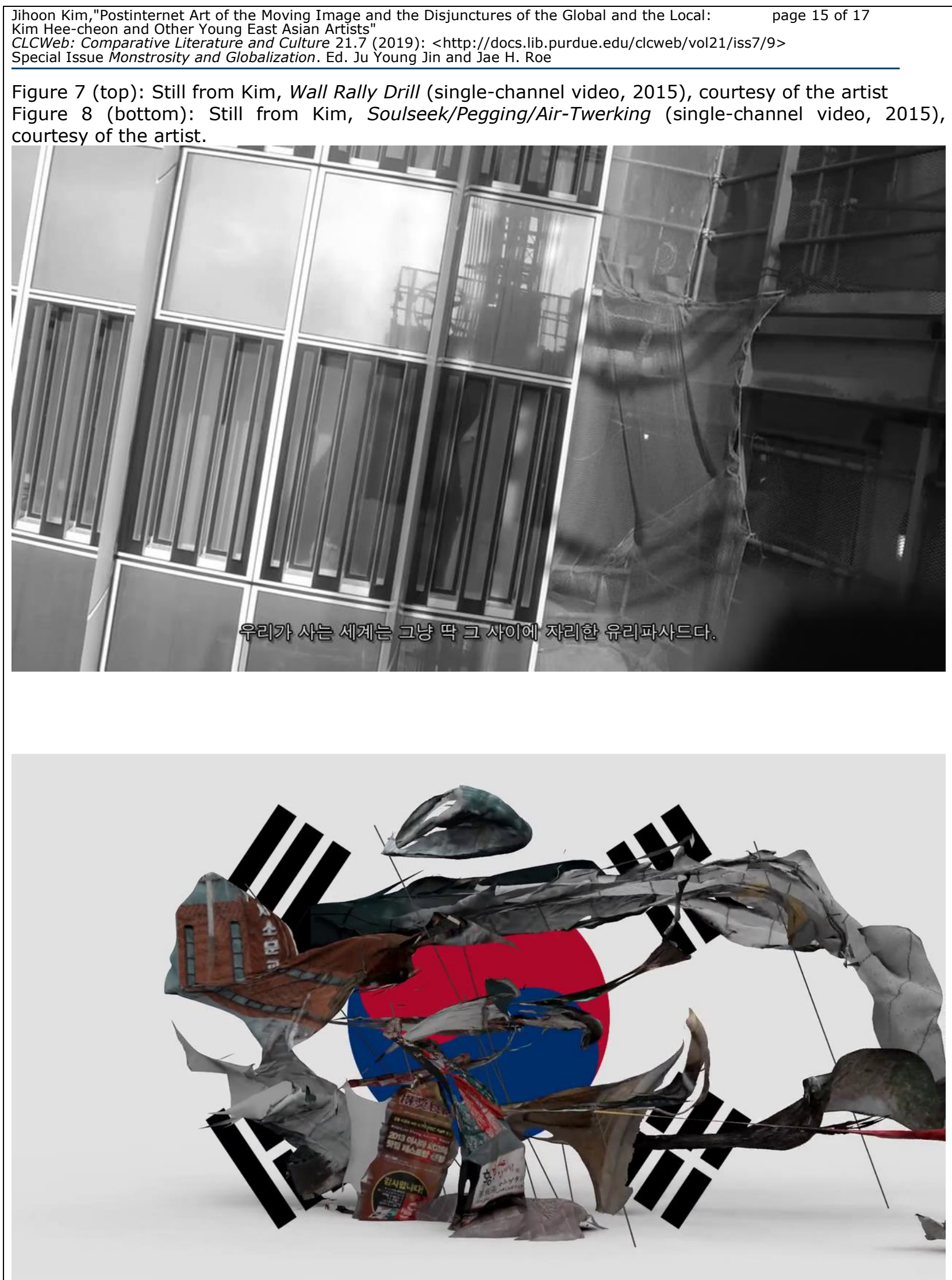

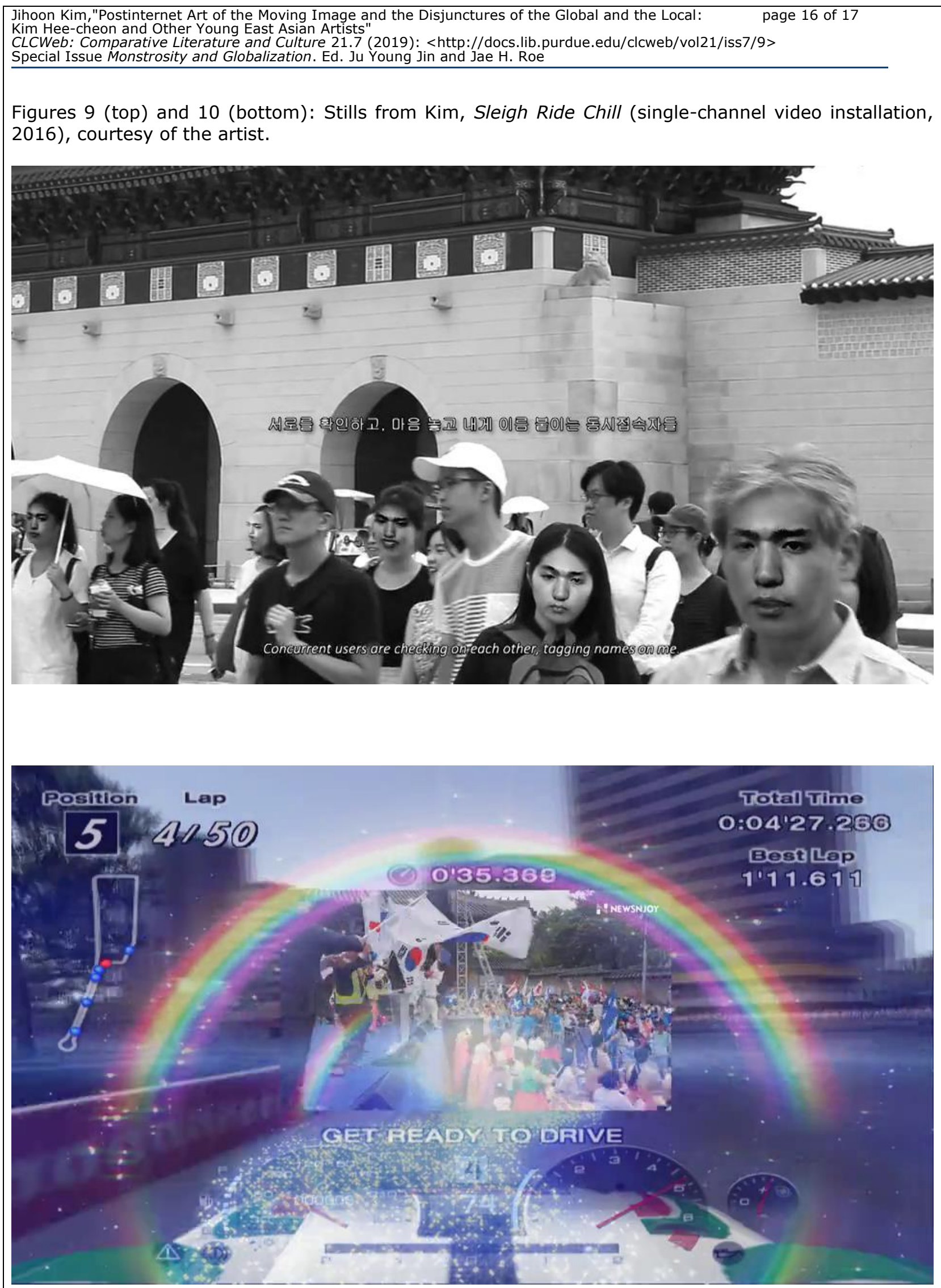
Author's profile: Jihoon Kim is Associate Professor of Cinema and Media Studies in the Department of Film Studies at Chung-ang University. He is the author of Between Film, Video, and the Digital: Hybrid Moving Images in the Post-media Age (New York: Bloomsbury Academic, 2018/2016). His essays on film theory, experimental film and video, art of the moving image, cinema and contemporary art, digital cinema, and experimental documentary have appeared in Cinema Journal, Screen, Film Quarterly, Camera Obscura, Animation: An Interdisciplinary Journal, Millennium Film Journal, Journal of Chinese Cinemas, and the anthologies Global Art Cinema: New Histories and Theories (Oxford University Press, 2010), and Taking Place: Location and the Moving Image (University of Minnesota Press, 2011), among others. Currently he is working on two book projects, each entitled Documentary's Expanded Fields: New Media, New Platforms, and the Documentary and Post-Verite Turns: Korean Documentary Cinema in the Twenty-First Century respectively. Email: <jihoonfelix@gmail.com> 